\title{
Ruth Irelan Knee: Influencing Progress in Mental Health
}

\section{Kenneth R. Wedel}

\begin{abstract}
Ruth Irelan Knee (1920-2008) was a major player and eyewitness observer of dramatic changes in the treatment of the mentally ill. Early on in her career she experienced interdisciplinary treatment for the mentally ill and organized efforts for addressing mental health and other afflictions, which confront families and communities. She believed that social work could be at the forefront in developing rational approaches to addressing mental health and other social issues through community development. And she placed great value in having social workers at the table with other disciplines to accomplish needed change. Throughout her career and life she stood out as an extraordinary advocate for her chosen profession.
\end{abstract}

Keywords: Ruth Knee, mental health legislation, treatment for mental illness, social work in mental health, long-term care ombudsman

Ruth Irelan Knee was born and raised not far from Tulsa, in Sapulpa (Creek County), Oklahoma. She took pride in the fact that she grew up in what had been Indian Territory and maintained a great respect for the Tribal people that had earlier been relocated there. Ruth and her older sister, Marie, enjoyed the advantages of a happy childhood provided by caring and educated parents during a period of relative prosperity for middle-class families in her locality. Her father was a newspaperman, oilman, church and civic leader. Her mother was a member of several civic clubs, school board member and active church member. Throughout her life Ruth maintained contact with Sapulpa classmates and made regular pilgrimages to her beloved home town.

By the time Ruth had passed the teenage years, she had witnessed dramatic changes in the social conditions of her home state; one that suffered greatly as the result of the "dust bowl" and "great depression." In preparation of editorials for the paper, her father shared stories about the effects of economic stress that had a strong influence on Ruth and her sister. Her mother's activities in charitable causes further shaped a character trait for "assisting people in need." When Ruth entered the University of Oklahoma, she followed her sister's choice to major in Social Work, where she received the Bachelor of Arts degree in 1941, and following a year of graduate work, the certificate in Social Work in 1942. She graduated Phi Beta Kappa. It was during her college days that Ruth met a fellow social work student through activities in the "Social Work Club," Junior K. Knee, who eventually became her husband and lifetime companion in social advocacy.

At the University of Oklahoma the school's director and professor, Dr. J. J. Rhyne, stressed the importance of social statistics in advocating for improving the state's welfare. Students were required to become involved in collecting statistical indicators to define social problems of their communities as a prerequisite in fashioning potential

Kenneth R. Wedel, Ph.D., is a Professor Emeritus and Coordinator of the Knee Center for Strong Families in the Anne and Henry Zarrow School of Social Work at the University of Oklahoma in Norman, OK. The author wishes to give recognition to the following individuals for their assistance in gathering information and reviewing draft versions of the manuscript: Ina Javellas, retired mental health social worker and Social Work Pioneer; Stephanie Winfrey and Chloe Kliewer, graduate MSW students and Knee Scholars. 
solutions. Dr. Rhyne led by example with his book, Social and Community Problems of Oklahoma, a publication filled with Oklahoma statistical data at that time (Rhyne, 1929). The use of statistical data in advocacy remained a feature of Ruth's work. She recalled her first field work experience as an undergraduate student during the Depression in the depravation of so-called "Hoovertown," along the river in Oklahoma City. "Just getting food was a major problem” (Stephenson, 1986).

Ruth earned her Master's degree in Social Service Administration from the University of Chicago. There she gained academic exposure to renowned faculty: Charlotte Towle, Edith Abbott, Helen Wright, and Wilma Walker, among others. The credo of that era was "responsible, accountable public service: help out where the people need you" (Coyne, 1986). Ruth reminisced about her graduate education experience at an award banquet held by the University of Chicago Club of Washington DC:

I enrolled in SSA in June 1942 - as a second year student (My earlier graduate work had been at the University of Oklahoma). It was a total cultural change. Of course, the whole country was changing. It was Wartime. This was reflected everywhere in Chicago. Chicago was a very large city. For the first time in my life, I was in an integrated setting - in the classroom, in stores, and streetcars - in the fieldwork setting. There were many adjustments to be made in daily living-as well as in how I studied. In SSA - we were not just studying textbooks - we were being taught by the authorities who had written the texts. About half our time was spent in field work - I was assigned to the Illinois Neuropsychiatric Institute - then a very new research/teaching hospital of the University of Illinois (Knee, 2000).

That field experience led to her first professional employment, which was with the Neuropsychiatric Institute.

The Institute had recently been established (1942) under the auspices of the Illinois Department of Public Welfare and the University of Illinois, Chicago (UIC). It was a joint venture between the UIC departments of Neurology and Psychiatry. Ruth recalled that Charlotte Towle had recommended that she accept a position there. Ruth held the job titles of Psychiatric Social Worker and Assistant Supervisor, Social Work Service. This early work history exposed Ruth to an interdisciplinary approach to the treatment of the mentally ill. The mission of the Institute was to study mental and nervous disorders and provide psychiatric training for practitioners.

Francis Gerly, MD, first chairman of the Department of Psychiatry, brought together an interdisciplinary group that included Franz Alexander, founder of the Chicago Psychoanalytic Institute; W. S. McCullough, MD, DPH, who developed computational models of brain function; Ladislas van Meduna, MD, developer of metrazol, convulsive shock therapy, and other organic therapies for medical psychosis; and Abraham Low, MD, who developed the recovery method of selfhelp for recently discharged psychiatric patients (UIC Department of Psychiatry, n.d.). 
The value of an interdisciplinary approach for addressing mental illness and other social ailments remained a focus of her advocacy throughout the years. Later, Ruth would reminisce that "family work was the focus then, when 25-page social histories were commonplace and the worker really got to know the whole family fabric after hours and hours of intense interview” (Coyne, 1986, p. 4).

\section{The Federal Government in Mental Health}

In 1944, Ruth moved to the nation's capital and began a distinguished career in the federal service. She and her husband, Junior Knee, built their lifetime home in Fairfax, Virginia, on the property they named "okie acre," in affection for their common roots in Oklahoma. Throughout their lives this home became the meeting place for family and friends, colleagues, and visitors from throughout the world. During this time she began networking through involvement in professional associations and social organizations. She was a member of the National Society of Daughters of the American Revolution and became involved in the Vienna Presbyterian Church, Vienna, Virginia, where she would eventually become a deacon; the Oklahoma State Society of Washington, DC; and the Mantua Woman's Club, Fairfax, Virginia. While some social workers would later become critical of their colleagues who were involved in what appeared to be "uppity conservative" organizations, Ruth believed such organizations would be positively influenced by the progressive philosophy that a social worker could bring to that environment.

Ruth began her career in DC when she was offered a position in the U.S. Public Health Service. In that setting, she became Chief Psychiatric Social Worker, Federal Employees Mental Hygiene Clinic, Public Health Service Dispensary, Washington, DC. Ruth's reflection on the experience is noted in the following (DuMez, 2003):

This wartime program had been established at the behest of Eleanor Roosevelt. She had become aware of the many physical and mental health problems experienced by the young people (mostly young women) from all over the country who had left their home for the first time in their lives in order to help the war effort in the nation's capital. The Mental Hygiene Control Unit was one of the first industrial mental health clinics in the country. It was a forerunner of employee assistance programs, as they are known today. One of our goals was to minimize job absenteeism in the federal agencies. As a social worker, I spent most of my time in intake evaluations and interpreting clinic recommendations to the referring agency counselor or nurse. They were very few community social or mental health resources that could be used for follow up (p. 85).

Employment in the agency served Ruth with the opportunity to sharpen her skills in clinical practice.

In 1949, Ruth's career took a significant turn with her appointment as Psychiatric Social Work Associate, Walter Reed Army Hospital. Walter Reed at the time was one of four training centers for military social workers, and "much of her time there was spent in working out a professional development program for military social workers, officers, and technicians" (University of Oklahoma Association, 1961, p.3). The Walter Reed 
program serves as one timid example of federal involvement in funding and promoting mental health. In 1851, U.S. President Franklin Pierce, vetoed legislation that would have provided federal funding in the form of land grants and income derived therefrom for states' public care of the indigent mentally ill. Federal support for mental health languished for the next century, until modest increments appeared, mostly for research relating to psychiatric disorders and the development of more effective methods of prevention, diagnosis, and treatment. As noted by Levine (1981), "[f]rom 1830 to 1945, there were no real developments in mental health services affecting the general public" (p. 31).

Mental health policy and programming can be seen as connected to health promotion principles. It was a theme promoted throughout Ruth's career, and quite naturally reinforced by the fact that her husband dedicated his career in public health. Vandiver (2009) categorizes the health promotion principles as involving individual and community level change. At the intersection of health promotion principles, processes and public mental health policies are three processes: (1) legislative, (2) regulatory, and (3) judicial. An example of the legislative process is the National Mental Health Act of 1946. An example of the regulatory process is Title V of the Public Health Services Act, requiring states' plans for comprehensive community mental health services. Examples of judicial processes include court cases such as Wyatt v. Stickney [1970], involving criteria for evaluation of care in psychiatric hospitals. Each of the processes and examples identified above (Vandiver, 2009) would play a key role in Ruth's career path in mental health.

A significant legislative breakthrough occurred before the decade of the 1940s closed. As a result of the National Mental Health Act of 1946, the National Institute of Mental Health (NIMH) was formally established in 1949. In 1955, the Mental Health Study Act with leadership from NIMH called for "an objective, thorough, statewide analysis and reevaluation of the health and economic problems of mental health" (National Institute of Mental Health, 2013). As a result, the Joint Commission on Mental Illness and Health was formed. It was in that same year (1955) that Ruth's career with NIMH began. Once again she would be involved in a collegial relationship with interdisciplinary professionals in a newly formed agency with fresh energy and creative ideas. This setting became the centerpiece of Ruth Knee's career. There she observed and was involved in the changes in mental health that occurred until her retirement form NIMH in 1972. During this phase of Ruth's career, a decline was occurring in the use of state public mental hospitals as the sole resource for the care of the mentally ill in the United States. Contributing factors were several, but especially the discovery of psychoactive drugs which became available to stabilize patients with psychotic disorders. Another major contributing factor was the involvement of the federal government in funding community mental health centers throughout the U.S. and financing services through Title XVIII and XIX of the Social Security Act-Medicare and Medicaid.

Reporting on recent advances at the time in the care and treatment of the mentally ill (Knee, 1959), Ruth identified emerging patterns. In the report, she noted that the concept of change over the past fifteen years was "perhaps the most significant in the care for the mentally ill - because for too long, things had appeared to be frozen and immobile" (p. 
51). A ray of hope, however, was seen in her work on a multidisciplinary team whose responsibilities included the provision of staff services for the initiation and development of the Mental Health Project Grant's program under Title V of the Mental Health Act. Ruth could proudly relate the involvement of social workers regarding the program.

There are social workers involved as staff members on a majority of all-current projects with many different functions and roles. In a number of projects, a social worker is the program director or codirector. In others, social workers are working in case finding, community organizations, and in the development of therapeutic programs. In a few, social workers are responsible for the evaluation of service (Knee, 1959, p. 59).

Regarding current developments in treatment at that time, the following listing was given by Ruth (Knee, 1959) as specific contributing factors in advancing understanding of mental illness from biological, social, and psychological standpoints and of the interrelationships of these influences upon behavior:

1. Impact of the contribution of social science theory to the understanding of mental illness upon the practice of psychiatry as a branch of medicine, and upon the other mental health professions.

2. Awareness of the importance of social relationships in the etiology of mental illness and in its treatment.

3. Study of the mental hospital as a social institution.

4. Recognition that certain practices that had long been accepted as a part of treatment (or hospitalization) probably contributed more to chronicity and social crippling than the disease itself.

5. Development of a broader philosophy of rehabilitation.

6. Recognition of the importance of a therapeutic environment - in the hospital, in the family, and in the community.

7. Increased use of group techniques in treatment.

8. Extension of the traditional "clinical team" of doctor, nurse, social worker, and psychologist to include persons with many other skills - the psychiatric aide, the rehabilitation specialist, the occupational therapist, the industrial therapist, the recreational worker, the volunteer, the social scientist- with concomitant changes in roles and responsibilities of team members.

9. Differential services related to the concept of comprehensive care and the continuum of the patient's needs as he moves from health to illness - and returns to health - or remains chronically disabled. Closer integration between the mental hospital and the total community is a prerequisite to continuity of care.

10. Utilization and availability of tranquilizing drugs. 
11. Introduction of public health concepts in the planning for, and development of, treatment and rehabilitation services as well as in efforts toward prevention and promotion of health.

12. Recognition of the unique needs of special problem areas, such as, aging, alcoholism, and mental retardation (pp. 51-52).

The following were also observed by Ruth (Knee, 1959) as patterns pointing to areas in which exploration and experimentation were being concentrated and gave promise for lasting acceptance:

1. Changes in the Traditional Mental Hospital

From the advantage of hindsight, it almost appears that the social movement, which encouraged each state to assume responsibility for the care and the treatment of the mentally ill through the establishment of state tax supported hospitals, carried with it certain negative aspects. The hospitals became larger and larger - and like malignant tumors, were not really interacting, functioning organisms within society. The concepts of the "open” hospital, increased patient freedom and improved staff-patient relationships are major themes in the transition from concentration on custody to emphasis on treatment and rehabilitation.

2. Treatment of Acute Illness

Twenty years ago there were fewer than fifty psychiatric units in general hospitals throughout the United States. In 1958, there were almost a thousand general hospitals - that would accept psychiatric patients.

3. Alternatives to Hospitalization

A variety of treatment and rehabilitation services are being developed that are designed to shorten or to make full-time hospitalization unnecessary, or to be used before or after hospitalization for an acute phase of illness. These include day hospitals, "half-way" houses, social therapeutic clubs, and rehabilitation workshops.

4. Community Planning for Mental Health Services

There is increased recognition of the imperative need for coordinated planning of services for the mentally ill.

5. Long-Range Planning

Several major studies have been in process in recent years which will have far-reaching effects in the direction of planning and establishment of services for the mentally ill. The World Health Organization, the U.S. Joint Commission on Mental Illness and Health (1956), and in England, the Royal Commission Report in 1956 were cited (pp. 56-57).

The next decade (1956-1966) was witness to what may be considered the greatest expansion of federal funding for the mentally ill. In 1963 Congress passed the 
Community Mental Health Centers Act (P.L. 89-97) authorizing construction grants for community mental health centers. A year later (1965), Medicare and Medicaid (Title XVIII and Title XIX of the Social Security Act) were enacted. Together, these laws and the regulations which followed changed dramatically the venues and funding for treatment.

\section{Community Level Treatment and Deinstitutionalization of State Hospitals}

Access to mental health treatment facilities was expanding between the late 1940s and 1960s. As an administrator of the Mental Health Project Grant's program under Title $\mathrm{V}$ of the Mental Health Act, Ruth played an important role in influencing the increase of local access to mental health treatment that could be observed during the decades following passage of the above program (Rice, Knee, \& Conwell, 1970).

In 1946, there were about 586,000 beds for the care of the mentally ill in the United States. About 80 per cent of these beds were located in state and county hospitals; the remaining 20 per cent were in private psychiatric hospitals. At that time, they constituted 42 per cent of all the hospital beds in the United States. There were known to be 315 public hospitals, 265 private hospitals, 109 general hospitals with psychiatric units, and 524 outpatient psychiatric clinics - a total of over 1,000 facilities. By 1967, the number of such psychiatric facilities had increased to over 4,000, including 1,316 general hospitals with psychiatric services and 2,213 outpatient psychiatric clinics. In addition, there were over 500 partial hospitalization services, mostly day hospitals. Funds for the construction and/or staffing of 351 comprehensive community mental health centers had been awarded by 1969 (Rice et al., 1970, p. 2247).

As noted above, while facilities for treatment of the mentally ill were expanding, traditional state hospitals experienced significant deinstitutionalization. In 1955, there were 559,000 beds in state mental hospitals in the U.S., representing 339 beds per 100,000 population. By December, 2000, the number of state mental hospital beds had dropped to 59,403. The change represented a drop to 22 beds per 100,000 population (Lamb \& Weinberger, 2005, p. 530).

\section{Funding for Treatment and Quality of Care}

In 1966, mandated mental health services were included in Medicare, and while the federal law does not contain explicit provisions concerning the exact types of mental health services that can be provided, all State Medicaid programs provide some mental health services to enrollees. Medicaid has become the single largest payer for mental health services in the United States (Medicaid, n.d.).

Following passage of Medicare and Medicaid in 1965, Ruth continued in a leadership role at NIMH in activities related to the regulatory process emanating from Title V of the Public Health Services Act. Specifically, she was in charge of planning and implementing the oversight of Medicaid funding for psychiatric facilities. At the time, The Joint Commission on Accreditation of Hospitals had no specialized standards for psychiatric hospitals. Few hospitals were accredited 
and general hospital standards were applied. An NIMH grant resulted in convening stakeholders for the purpose of drafting standards for psychiatric hospitals. Included in the efforts were participants from the American Psychiatric Association, American Psychological Association, National Association of Social Workers, American Nursing Association, Occupational Therapy Association, mental hospital administrators and public and private mental health programs. The draft that emerged described the documentation and staffing necessary to assure the psychiatric patients' effective treatment. The proposal was accepted by the Health Insurance Benefits Advisory Council and the then Secretary of Health, Education, and Welfare, Wilbur J. Cohen. The ongoing efforts resulted in the development of the special conditions of participation for psychiatric hospitals.

In addition, NIMH, through collaboration with other governmental agencies within the Public Health Service, the Social Security Administration and the Social and Rehabilitation Services provided consultation to state and local mental health programs for the interpretation and implementation of Medicaid standards. These efforts focused upon specific needs and unique approaches of mental health services delivery systems/programs. Policy makers as well as administrators of third-party payment programs participated. NIMH staff training programs, national and regional conferences for both state and mental health professionals and administrators in public and private sectors were held. Reimbursement studies, utilization review problems, approaches for quality assurance and therapeutic approaches for the elderly mentally ill were addressed.

Finally, in 1969, the Bureau of Health Insurance, Social Security Administration and the then Health Care Financing Administration (HCFA) requested NIMH to recruit a panel of specialized psychiatric consultants to conduct surveys of psychiatric facilities. Two conditions were required for the facilities to receive federal Medicare reimbursement for mental health services provided. The conditions concerned adequate standards for staffing and for record keeping (Centers for Medicare \& Medicaid, n.d.). These "survey teams" would determine whether or not the hospital met the Five Special Conditions of Participation. Initially a Joint Interagency Agreement was enacted between then HCFA and NIMH; later it became solely HCFA, and most recently the Centers for Medicare and Medicaid Services. Initially NIMH agreed to provide qualified mental health professionals to assist the state's licensure and certification agencies and the then HCFA Regional offices in the actual performance and assessment of Medicare surveys of Psychiatric Hospitals. The survey program continues to this date and is administered by the Centers for Medicare \& Medicaid (I. Javellas, personal communication, August 21, 2013).

Mental health professionals (e.g., Ruth and her colleagues) found a guiding philosophy for professional standards for quality care in the statement of Chief Judge David L. Bazelon of the U.S. Court of Appeals, Washington, DC. 
To provide adequate treatment, the critical requirement is, that the hospital pay individual attention to each patient and make an individualized effort to help him. There may be certain gross benchmarks to which a court may look in scrutinizing the adequacy of treatment at a hospital - the ratios of professional and paraprofessional staff to patients, the physical facilities for treatment, the overall level of expenditures within the hospital. But there is only one way to measure treatment provided. If there is an individualized treatment plan created at the inception of treatment and modified as treatment progresses, a reviewing court can hope to assess whether a bona fide effort to provide a meaningful amount of some appropriate form of treatment has been made.

To perform this task, the judge need not be or even pretend to be a psychiatrist. His role is not to make independent judgments concerning treatment, but rather to scrutinize the record to insure that an expert more qualified than he has made a responsible exercise of his professional judgment (Burris, 1969, p. 3).

A particularly significant outcome for patients' right to treatment, and quality of care conditions set forth for the survey process resulted from the court case of Wyatt $v$. Stickney. The case involved Ricky Wyatt, who at fifteen was institutionalized at Bryce Hospital in Alabama. Wyatt had been incarcerated for "delinquency" but had never received any other diagnosis of mental disability or condition. He and his aunt (a former employee) testified about the intolerable conditions and lack of therapeutic treatment at the hospital under supervision of state mental health commissioner, Stonewall Stickney (Carr, 2004).

The suit initially was prompted by layoffs at Bryce Hospital, with attorneys alleging that insufficient staff at the hospital would prevent involuntarily committed mentally ill patients from receiving adequate treatment, a violation of their civil rights under the Fourteenth Amendment of the U.S. Constitution. Federal District Court judge Frank M. Johnson Jr. ruled in favor of the plaintiffs, concluding from evidence submitted during litigation that standards for adequate treatment did not exist (Encyclopedia of Alabama, 2009).

During the lawsuit, Ruth Knee and other mental health professionals gave expert testimony on standards for care of people with mental health and mental retardation residing in institutional settings. The standards which became known as the "Wyatt Standards," cover three fundamental areas: individualized treatment plans, qualified staff in numbers sufficient to administer adequate treatment, and humane psychological and least restrictive environments (Prigmore \& Davis, 1973).

\section{Advocacy for Social Work}

With federal funding for expansion of mental health facilities and services, social work experienced a rise in services for the mentally ill. Social work originally was formally undertaken in psychiatric hospitals, and with a limited function. But the infusion of federal funds presented an opportunity for the profession to create an area of turf. "The social worker was first added to the staff of the hospital to follow patients discharged from care in order to assist with their adjustments when they returned to their families 
and communities" (Vourlekis, Edinburg, \& Knee, 1998, p. 573). Interest in aftercare for the mentally ill surfaced in the United States in the late $19^{\text {th }}$ century, and expanded in some states in the first decades of the $20^{\text {th }}$ century. As noted previously, by the 1940 s and 1950s, with the advent of the Mental Health Project Grants program, social workers as staff members of new projects began fulfilling increasing functions and roles. However, by 1998, Ruth and her colleagues would advocate:

As state Medicaid programs move to private managed care models, it is critical that the profession promote understanding, strongly advocate for this population, and build social work functions - among them case management - that adequately and realistically address the comprehensive biopsycho-social needs of people with serious and persistent mental illness. Social Work has a clear and compelling action agenda with significant implications for client care and for professional turf (Vourlekis et al., 1998, p. 573).

As a Social Work Pioneer, Ruth gave perspective to her career in mental health and the developments through the years:

My federal career provided me with many interesting challenges. When I joined the staff of the National Institute of Mental Health in 1955, my focus became mental health issues of concern across the country. This was the advent of the use of psychotropic drugs in the treatment of psychiatric problems. State hospitals were filled to overflowing with chronically mentally ill patients. I was the psychiatric social worker on a 'mental hospital improvement' team, which included a psychiatrist, a clinical psychologist, and a psychiatric nurse. Our mission was to identify useful approaches and new modalities that were being used effectively and to communicate these ideas to administrators and staff of hospital and community programs throughout the country. The new approaches included after-care programs, social rehabilitation units, halfway houses, and vocational rehabilitation programs. We traveled a lot, identified positive change, and documented serious problems. Some said we were like honeybees, gathering the pollen of ideas and then spreading it around.

Development of community-based mental health resources became the national priority for mental health service in the 1960's. This is still a work in progress. Deinstitutionalization, third-party payments, changes in federal and state mental health and social service responsibilities and funding, and advances in knowledge about mental disabilities have brought about many changes in community care systems. I suppose one of the things that I am most proud of was my role in networking and in facilitating innovative approaches to 'improvements'. In addition to being 'honeybees,' my colleagues and I were 'mental health missionaries’ (DuMez, 2003, p. 85).

Through her professional leadership, Ruth was in an advantageous position to advocate for social work in mental health and other emerging areas. She was a member of a number of professional organizations and emerged as a leader of several. As a member of the American Association of Psychiatric Social Workers, she served as president from 1951 to 1953. In the two years following, she was active in efforts to merge that 
association and several others into the National Association of Social Workers (NASW) in 1955. Ruth remained a dedicated and active member of NASW until the time of her death. Among the numerous leadership functions she fulfilled in NASW, the following are included: the organization's first secretary; member of the executive committee and board of directors in 1955-57, and again in 1984-86; and representative from Region V, the metropolitan Washington, DC chapter. At the conclusion of the latter office, she received a salute from members of the Region:

A "founding mother" of NASW, Ruth I. Knee is more than just a footnote in the annals of social work history. This extraordinary woman, who just turned 66, has recently received a Certificate of Recognition from the NASW Board of Directors.

Her multifaceted resume is full of councils, and committees, task forces and research projects, running the gamut from quality care issues to mental patients and long term care for the aged (Coyne, 1986, p. 4).

The Ruth Knee/Milton Whitman Health/Mental Health Achievement Awards program was established in 1989 by the Board of Directors of NASW to honor the outstanding careers of these two pioneering social workers. Since its inception, this distinguished awards program has annually recognized individuals for their lifetime achievement in health/mental health practice and for outstanding achievement in health/mental health policy. Ruth was a co-founder and recipient of The Social Work Pioneer Program, created in 1994 to honor members of the social work profession who have contributed to the evolution and enrichment of the profession. The Pioneer Program identifies and recognizes individuals whose unique dedication, commitment and determination have improved social and human conditions, and serve as role models for future generations of social workers.

Following her retirement from NIMH in 1972, Ruth would relentlessly continue in advocacy roles in the federal service. During the decade of the 1970s and beyond, Ruth occupied positions that related to concerns of the aged and their experiences with mental illness and long-term care. Out of that work Ruth revealed a strong passion for societal safeguards to enhance quality of care and protection for the elderly. In a 1977 document, Ruth relates to the national concern as to how best provide long-term care that is responsive to the idiosyncratic needs of a rapidly aging population, including individuals with disabilities and chronic "inabilities" who become dependent.

...many professionals, consumers and members of the community-at-large are demanding that more than sustenance be provided in long-term programs. "Custodial" is now an unspoken, unpopular word, as people have come to recognize that even a bleak and marginal existence can be improved through concentration on "quality of life," through humanizing the process of institutionalization, de-institutionalization, the delivery of services, routine and otherwise, in any environment to the ill, the infirm, the poor, and the isolated (Health Resources Administration, 1977, p. vii). 
Ruth and her social work colleagues were influential in promoting patient rights for individuals as they enter and interact with health and mental health care systems. They especially focused on supporting a "bill of rights" for nursing home patients, which in 1980 were contained in the Civil Rights of Institutionalized Persons Act (CRIPA). Amendments to that Act in 1987 are collectively known as the Federal Nursing Home Reform Act included as part of the Omnibus Budget Reconciliation Act (OBRA). Closely related to patient rights was promotion of an ombudsman function for nursing homes. The Long-Term Care Ombudsman Program (OAA, Title VII, Chapter 2, Sections 711/712) began in 1972, and is included in the Older Americans Act (Administration on Aging, 2013).

As a public servant working for the U.S. Public Health Service, Ruth Knee became the first coordinator of this nationwide program which was later transferred to the U.S. Administration on Aging. Ruth continued her highly respected work with the program until she retired. Her guidance was fundamental to the continued successful expansion of the innovative program. The National Citizens' Coalition for Nursing Home Reform (NCCNHR) (which I founded in 1975) established a national advocacy award in the early 1980's. Ruth, who was often referred to fondly as 'the grandmother' of the ombudsman program was an early recipient of this award. Soon after this, Ruth began giving an annual donation to fund the award which would always honor a local or state ombudsman. Ruth herself later requested that the award be renamed as the Cenoria Johnson Advocacy Award when her former co-worker in the ombudsman program died (E. Holder, personal communication, August 23, 2013).

A close colleague sums up the contributions Ruth made in her untiring efforts as a mentor and advocate for improving the lives of individuals requiring institutional care. "Ruth was one of the greatest mentors of all time for those of us who worked with her. Her role in the federal government improved the quality of life for people of all races in the U.S. requiring services of long term care, especially for the mentally ill (B. Harper, personal communication, July 29, 2013).

Ruth's professional values correlated with her personal commitments and generosity. In 1982, she donated the Irelan family home of her youth in Sapulpa, Oklahoma, to the Sapulpa Handicapped Opportunity Workshop Corporation. The home serves as a group home living arrangement for the developmentally disabled. Endowment funds were provided to the social work educational programs from which she had graduated. At the University of Chicago, School of Social Service Administration, she provided funding for a lectureship in spirituality. And, at The University of Oklahoma, Anne and Henry Zarrow School of Social Work, she willed her estate in 2008. As a result, the School has established the Knee Center for Strong Families, dedicated to building theory, knowledge, practice and education for development of strong families in their diverse forms.

During her lifetime, Ruth received many honors and awards related to her advocacy for mental health, the profession of social work, and quality of care for individuals in 
long-term care. Appropriately, late in her career she was one of the first women to be admitted to the prestigious Cosmos Club of Washington, DC. The Cosmos Club is a private social club that through the years has included as members U.S. Presidents, Vice Presidents, Supreme Court Justices, Nobel Prize winners, Pulitzer Prize winners and recipients of the Presidential Medal of Freedom. Membership in the Club is reserved for persons of "distinction, character and sociability." Criteria for membership include persons who have "done meritorious original work in science, literature, or the arts; though not professionally occupied in science, literature or the arts, is well known to be cultivated in some field thereof; or, is recognized as distinguished in a learned profession or in public service" (Cosmos Club, n.d.). Ruth served on the program planning committee, and enjoyed the opportunity to suggest topics of social awareness at program events.

Today, a mental health challenge can be observed in the dismal statistics that reveal a trend for incarceration of the mentally ill.

Severely mentally ill individuals who formerly would have been psychiatrically hospitalized when there were a sufficient number of psychiatric inpatient beds are now entering the criminal justice system for a variety of reasons. Those most commonly cited are: (1) deinstitutionalization in terms of the limited availability of psychiatric hospital beds; (2) the lack of access to adequate treatment for mentally ill persons in the community; (3) the interactions between severely mentally ill persons and law enforcement personnel; and (4) more formal and rigid criteria for civil commitment (Lamb \& Weinberger, 2005, p.530).

If Ruth Knee were living today, she would likely be at the forefront with her social work colleagues in her words to "rattle a few cages" for change.

\section{References}

Administration on Aging. (2013, July 18). Long-Term care ombudsman program (OAA,Title VII, chapter 2, sections 711/712). Retrieved from http://www.aoa.gov/AoA programs/Elder Rights/Ombudsman/index.aspx

Burris, D. S. (Ed.). (1969). The right to treatment: A symposium. New York, NY: Springer Publishing Company, Inc.

Carr, L. W. (2004, July). Wyatt v. Stickney: A landmark decision. Alabama Disabilities Advocacy Program. Retrieved from http://www.adap.net/newsletters/2004adapnews/newsletter7-04.pdf

Centers for Medicare \& Medicaid Services. (n.d.). Medicare benefit policy manual: Chapter 2- Inpatient psychiatric hospital services. Retrieved from http://www.cms.gov/Regulations-andGuidance/Guidance/Manuals/Downloads/bp102c02.pdf

Cosmos Club (n.d.).Membership. Retrieved from https://www.cosmosclub.org/Default.aspx?pageindex=1\&pageid=67\&status=1 
Coyne, B. L. (1986, June-July). Metro Washington chapter salutes Ruth Knee. The Bulletin. National Association of Social Workers: Metropolitan Washington Chapter, p. 2.

DuMez, E. W. (2003). Ruth Knee. In E. W. DuMez (Ed.), Celebrating social work faces and voices of the formative years (pp. 84-85). Alexandria, VA: Council on Social Work Education.

Encyclopedia of Alabama. (2009). Wyatt v Stickney. Retrieved from http://www.encyclopediaofalabama.org/face/Article.jsp?id=h-2375

Health Resources Administration, Division of Long-Term Care. (1977). The future of long-term care in the United States - The report of the task force. National Conference on Social Welfare (NTIS No. HRP-0016874).

Knee, R. I. (1959). Recent advances in the treatment of the mentally ill. In Education for social work: Proceedings of the Seventh Annual Program Meeting, Philadelphia, PA, (pp. 51-61). New York, NY: Council on Social Work Education.

Knee, R. I. (2000, April). Awards banquet. Unpublished notes, The University of Chicago Club of Washington, DC.

Lamb, H. R., \& Weinberger, L. E. (2005). The shift of psychiatric inpatient care from hospitals to jails and prisons. The Journal of the American Academy of Psychiatry and the Law, 33(4), 529-534.

Levine, M. (1981). The history and politics of community mental health. New York, NY: Oxford University Press, Inc.

Medicaid.gov. (n.d.). Mental health services. Retrieved from http://www.medicaid.gov/Medicaid-CHIP-Program-Information/ByTopics/Benefits/Mental-Health-Services-.html

National Institutes of Health. (2013). National Institute of Mental Health: Important events in NIMH history. Retrieved from http://www.nih.gov/about/almanac/organization/NIMH.htm

Prigmore, C. S., \& Davis, P. R. (1973). Wyatt v. Stickney: Rights of the committed. Social Work, 18(4), 10-18.

Rhyne, J. J. (1929). Social and community problems of Oklahoma. Guthrie, OK: Cooperative Publishing Co.

Rice, D. P., Knee, R. I., \& Conwell, M. (1970). Financing the care of the mentally ill under Medicare and Medicaid. American Journal of Public Health, 60(12), 22352250.

Stephenson, M. (1986, May 26). A woman with a mission. Tulsa World, p. 2.

UIC Department of Psychiatry College of Medicine. (n.d.). History, neuropsychiatric institute. Retrieved from http://www.psych.uic.edu/aboutus/history 
University of Oklahoma Association. (1961, November). Knee key team member of multidisciplinary group. Sooner News-Makers, 3(2), 2. Norman, OK: The Transcript Press.

Vandiver, V. (2009). Integrating health promotion and mental health. New York, NY: Oxford University Press.

Vourlekis, B. S., Edinburg, G., \& Knee, R. (1998). The rise of social work in public mental health through aftercare of people with serious mental illness. Social Work, 43(6), 567-575.

\section{Author note}

Address correspondence to: Kenneth R. Wedel, Ph.D., University of Oklahoma, Anne and Henry Zarrow School of Social Work, 700 Elm Avenue, Norman OK 73019. Email: kwedel@ou.edu

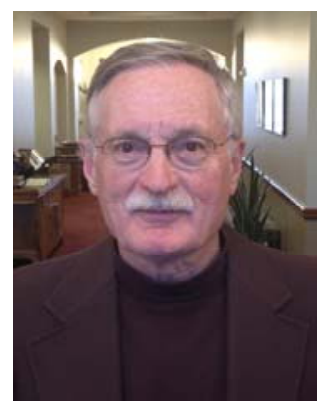

Kenneth R. Wedel is Professor Emeritus and Coordinator of the Knee Center for Strong Families at the Anne and Henry Zarrow School of Social Work, University of Oklahoma. He received an MSW degree from Florida State University, and a Ph.D. in public administration from the University of Pittsburgh. He joined the faculty at the University of Oklahoma in 1979 and served as the School's Director (1979-86 and Interim Director 2000-2001). His professional practice experience includes social work practitioner, planner and administrator of social service programs. His teaching and research covers social policy and social program administration. 